\title{
Compatibility before Commitment: Do Couples Consider Compatibility before Marriage?
}

\author{
Emma Best-Prothero
}

\section{Abstract}

A major feature of intimate relationships is compatibility. It can be the catalyst for an intimate relationship, while incompatibility can hasten the termination of an intimate relationship. In 2011 a law firm in the United Kingdom released a list of questions which they recommended all couples address, to evaluate their compatibility prior to committing to each other. This recommendation infers that compatibility is static and cannot develop, as well as that a formalised discussion is the best manner in which to consider compatibility. This research project will explore the need to consider compatibility prior to commitment by addressing the research question: 'do couples consider compatibility prior to committing to marriage?' Utilizing a series of semi-structured, in-depth interviews with four couples who recently married, this research project concludes that compatibility within an intimate relationship is highly desirable, and is considered before committing to marriage. Indeed, individuals test and sample compatibility by cohabiting prior to commitment. At the same time, cohabitation strengthens and enhances compatibility.

\section{Introduction}

Compatibility is a major feature of intimate relationships. In the first days of dating compatibility can aid in ensuring the continuance of the relationship, while incompatibility can expedite a decision to end the relationship. In the later stages of a relationship, compatibility is valuable in aiding conflict resolution (Crawford, et al., 2002). The Oxford English Dictionary defines compatibility as the capacity for two things to exist or occur together without problems or conflict (Compatibility, 2011). Within an intimate relationship text books commonly refer to compatibility as the ability of two individuals to harmoniously exist within the relationship (Lindsay \& Dempsey, 2009). 
There are multiple sociological implications of compatibility, including: a) the role of compatibility within intimate relationships and how it is being capitalised, b) the value placed on compatibility and areas in which an individual wishes to be compatible with another, and finally c) the increasing number of individuals choosing to cohabit before, or in place of, marrying. Research has highlighted the potential for compatibility to be a catalyst to a relationship, and how this is being capitalised on within society (Lindsay \& Dempsey, 2009).

Individuals are often introduced to another because a mutual friend perceived them to be compatible, in hope they will 'hit it off' (Glick, DeMorest, \& Hotze, 1988). Compatibility has been capitalised through online information and communication technologies, particularly personality-matching dating websites, where individuals are matched based on compatibility of personality (Barraket \& Henry-Waring, 2008). Moreover, recent research has proposed a change in the value placed on compatibility, as well as ways in which individuals wish to be compatible. A 2004 study revealed approximately 30\% of participants felt they were very selective when it came to choosing a partner, desiring a highly compatible partner, rather than committing to a relationship for the sake of it (Qu, \& Soriano, 2004). Furthermore, Hughes (2005) has proposed the way in which individuals wish to be compatible with another may be influenced by the changing dynamics of modern relationships. Hughes noted within 'Generation $\mathrm{X}^{\prime}$, those born between 1965-1979, the ideas of gender roles, obligation and duty have been replaced with ideas of self-actualisation, of individuals as self aware autonomous beings, of contingency, and individualism. Thus, individuals may consider their compatibility with another more in terms of self-improvement, career ambitions, and individualism. Finally, much has been made of the relatively new norm of unmarried cohabitation; which is common in all age groups, but particularly amongst individuals in their 20s (Lindsay \& Dempsey, 2009). In 2006, $21 \%$ of men and women were in cohabiting relationships (Heard, 2008). It is feasible cohabiting affords couples the chance to test and determine the compatibility of a long term relationship without formally committing to each other.

At the same time research on compatibility has found incompatibility to be the second most cited reason for divorce, after infidelity (Amato \& Previti, 2003). Interestingly, it was within the context of incompatibility leading to divorce that Bross Bennett, a law firm in the United Kingdom released a list of questions they recommended all couples address prior to committing to each other. Presumably, they released the questions to highlight their understanding of the role of incompatibility in divorce, while promoting their services as divorce law experts. Within the press release Ruth Bross, a partner at the firm, equated committing to another person with hiring a new employee: 
No employer would offer someone a job without considering their suitability for that position and neither should a couple embark on a lifelong commitment without doing their research (Bross Bennett LLP, 2011).

By comparing committing oneself to another within an intimate relationship, to a job interview, Bross seemingly overlooks the emotions associated with relationships. Indeed, the list of questions, titled the 'Bross Bennett Compatibility Quiz' (BBCQ) (enclosed as Index I), reads like a list of questions asked of a potential employee, not a potential intimate partner. Additionally, the formalised recommendation from Bross Bennett infers that individuals are not considering compatibility before committing to marriage, and frames compatibility as static with no ability to develop during an intimate relationship.

Overlooking the blatant mistake of removing emotions from the emotionally heavy area of intimate relationships, the suggestion that individuals should, but do not, consider compatibility before marriage is worthy of exploration. The objective of the current study is to investigate whether couples do consider compatibility before marriage, and if so, how?

\section{Methodology}

As the aim of this research is to investigate whether couples consider their compatibility before committing to marriage, data was collected through conducting semi-structured, in-depth interviews with couples who had recently (within 18 months) married.

This research method was chosen due to the ability of interviews to elicit nuanced and detailed accounts of individual experiences, opinions and feelings - in partciular to address sensitive topics, such as whether individuals within the intimate relationship considered compatibility prior to marriage (Gorden, 1980). Furthermore, the in-depth interview aims to answer social questions through the understanding people bring to their interpretation of the social world (Travers, 2010). The semi-structured interview encourages participants to discuss their experiences, feelings and opinions through open-ended questions, with the ordering of future questions determined by the interviewee's response (Dearnley, 2005).

Four couples who were known to the researcher, and who had married within the 16 months prior to the interview, were interviewed. For the purposes of this research the couples will be identified with the pseudonyms Mr. and Mrs. Boulevard, Mr. and Mrs. Island, Mr. and Mrs. Maxwell and Mr. Avant and Ms. Becket. All four couples are in their mid to late twenties, living in Canberra, had 
cohabited for at least a year prior to marriage, and did not have children. At the time of the interview, at least one member of each couple worked within the Australian Public Service, and one or more individuals in each relationship had studied as well as worked full-time in the previous year.

All interviewees knew the researcher, though some relationships were dependent on the second partner. The partner who did not know the researcher independently, may have felt uncomfortable being interviewed alone. Although more results may have been produced by interviewing each partner individually and then as a couple, couples were interviewed together.

The four interviews were conducted at the interviewees' home over coffee and biscuits in their primary living area. This was done to maximise participant comfort and decrease participant anxiety. Moreover, in three of the four interviews, the interviewees' dog was also located in the primary living room for beneficence.

At the commencement of the interview, the researcher provided each participant with a copy of the BBCQ for reference and an overview of the research, including the purpose of the interview, the objectives of the research, an explanation of how the data collected would be used, the voluntary nature of participation, and how confidentiality would be assured. The researcher requested consent from the interviewees' to record the interview, and took the time to address any points of interest or questions raised by the interviewees. At this time, the researcher explained the concept of the BBCQ, and commenced the interview, asking the interviewees' a number of questions regarding their beliefs on compatibility, including their thoughts of the BBCQ and whether they considered their own compatibility before committing to marriage.

\section{Discussing Compatibility}

When asked to define compatibility each couple interviewed, identified compatibility differently; though all noted that being compatible did not mean agreeing all of the time. Indeed most listed having differences as a positive element of compatibility. Ms. Becket added that she believed compatibility embodied respect and compromise:

I don't think it's necessarily about wanting to do all the same things all the time together, and having the same views, it's more about being able to respect each other's views and if you disagree so be it, and if you need to find a compromise, you both find a compromise.

Mr. Island suggested that compatibility was a balance of being alike and unlike: 
I guess it's having enough in common to be able to do things together without fighting, and enough that is unique to find each other interesting and maintain your own individuality. I think if you were too similar you would spend all your time together and it would suck. And if you were too different you wouldn't be able to agree on anything and there would be constant conflict. So I think compatibility falls somewhere between being the same and being different.

Using their definition of compatibility, all couples believed they were compatible. When questioned on the specific characteristics of compatibility, a number of traits not normally considered in a dictionary definition were listed, including: respect, awareness, acceptance, compromise, patience, and support. The common characteristic listed by all participants, however, was individual identity - desired in both a partner and oneself.

We have always believed it's important to spend time apart and with other people, and it's important to have your own interests.

The fact that maintaining individuality was consistently listed as a compatibility trait supports Hughes (2005) finding on the importance of individuality for 'Generation X'.

Additionally, all participants said they felt knowing whether they are compatible with their partner was important to them, with each individual in the partnership considering their compatibility prior to committing to marriage, or prior to getting engaged. It was the experience of participants that compatibility could be discussed, analysed and determined organically in the relationship, without necessarily utilising a tool such as the BBCQ. Mrs. Boulevard said:

I think it would be important for people to have a vague idea of their partner's idea, and whether they are compatible on things, rather than blindly going into it. Knowing three people my age who are now divorced, I think there were things they could have picked up on earlier.

The importance of having an understanding of the compatibility within their relationship was expressed by all, with most couples suggesting it was beneficial to the investment (emotional, physical and financial) they were making within their relationship.

I think that people should consider it, because [on] a lot of these things, if your answers are different and you don't have a good way of dealing with it, they can be marriage breakers!

These references to divorce and 'marriage breakers' due to incompatibility, support the importance of considering compatibility prior to marriage, while highlighting the role of incompatibility within divorce. 
Another theme captured within all four interviews was the development of compatibility. All four couples were able to list at least one area where they felt they had become more compatible over time. Mr. Avant and Ms. Becket found they had become more compatible in leisure activities, through encouraging one another to try new activities. Mr. and Mrs. Island mentioned numerous times that they were able to track the development of their compatibility through their approaches to joint finances. They explained their compatibility had strengthened due to understanding each other's needs and expectations regarding finances and implementing systems that worked for both. Mr. and Mrs. Boulevard felt that their attitudes towards housework had become more compatible, putting the increased compatibility down to living together and understanding their partner in regards to how they had been raised by their parents and the roles they had seen their parents play. Mr. and Mrs. Maxwell noted they had become more compatible regarding family ties, with Mrs. Maxwell compromising with respect to the time spent with her immediate family.

I am trying to think of something, I guess in terms of the family stuff... well, we don't go every Sunday, we go sometimes, and other times I go by myself, so I guess that's give and take, it's just a compromise, everything is about a compromise.

Indeed, Mr. and Mrs. Boulevard, and Mr. Avant and Ms. Becket both suggested that living together prior to committing to each other in marriage had allowed them to explore and sample their compatibility, which may have helped them understand it better, and enable its development.

I think, in [the] modern day, because we lived together for 5 years before even getting engaged, you tend to figure out if you are compatible by that point or not anyway. So I guess it would be different, I guess using the job interview (analogy used in BBCQ), you could look at it as a 5 year long job interview before you have gotten married as opposed to sitting down with six questions on day three and answering the questions together... I think the more you live with someone, the more alike you become and the more your values align. Just from sheer interaction with that person.

We have been together for six years, almost six years before we got married, so I think they (issues of compatibility) were all ironed out beforehand.

The demonstration of the development of capability during an intimate relationship is significant to this research as well as future research on compatibility and cohabiting. 


\section{Conclusion}

This research explored compatibility within a committed intimate relationship by addressing the question: 'do couples consider compatibility before committing to marriage?' The findings of this research suggest that couples do evaluate compatibility before marrying, with compatibility within an intimate relationships being highly desirable. Couples believe it is necessary and beneficial to assess compatibility prior to marrying, as the failure to do so could lead to 'marriage breakers' or 'nasty surprises'. Moreover, evaluating compatibility also enables the development of conflict resolution within an intimate relationship. Finally, cohabiting prior to marriage allows for compatibility to be tested and sampled by both partners, and also facilitates the enhancement of compatibility.

The development of compatibility throughout an intimate relationship is sociologically relevant given the rising rates of divorce and the decreasing number of couples choosing to marry, and as such, should be central to future research. As the findings of this research cannot be generalised due to the small sample size and recruitment method, future research should first verify the results by replicating the present research with a larger random sample. The present research should then be expanded on to examine how and why compatibility develops over time. It is feasible that time spent together, shared experiences and/or joint emotional investments enhance compatibility within an intimate relationship. It is also equally plausible that a couple's incompatibility increases over time due to the same reasons. 


\section{Index I - Bross Bennett Compatibility Quiz (BBCQ)}

\section{Finance}

1. Do you know the extent of each other's assets?

2. How do you both view the sharing of these assets?

3. Do you have the same attitude to saving?

4. Will one of you want to put into a pension what the other wants to put into a new car?

5. Will you pool your resources or do you want to keep everything separate?

6. Joint accounts or separate?

7. Will you contribute in proportion to your incomes, or equally?

8. Are you going to have to pay off your partner's debts perhaps from what you thought was going to be the deposit on your house?

\section{Family Ties}

1. What sort of relationship do you have with your extended family?

2. Are they good at staying in touch?

3. Are they local?

4. Affectionate?

5. Over-involved?

6. Have you had any major fallings out?

\section{Children}

1. Do you want children?

2. How many?

3. How do you want to raise your children?

4. What sort of values do you want to pass on?

5. Do you have opposing views about the benefits of state versus private education and should you be thinking now about buying in a catchment area for a good state school? 


\section{Religion}

1. What are your religious views?

2. Do you agree on what religion you will bring up the children in?

3. Church/mosque/synagogue?

4. Once a week or once a year? Or no religion at all.

\section{Leisure and fun}

1. Do you like doing the same things in your spare time?

2. Do you share common interests?

3. Is your idea of a holiday lying flat on the beach for two weeks and your partner's rock-climbing?

\section{Lifestyle}

1. What sort of lifestyle are you aiming for?

2. Where do you want to live?

3. Do either of you have a dream of downsizing at some point and living away from the city?

\section{Spending}

1. Do you have an expensive shoe or gadget habit?

2. Does one of you think of a particular purchase as an essential that the other regards as a "discretionary spend"?

3. Do you have any other secret addictions: handbags, chocolate, football?

4. Do you gamble, online or otherwise? 
The ANU Undergraduate Research Journal

\section{Work}

1. Are your respective career paths compatible; is either of you going to have to make compromises?

2. Are you prepared to?

3. Will you want to give up work when you have children?

4. What does your partner think about this and can you manage financially?

5. What about part-time working?

\section{Roles: Traditional or Modern?}

1. Will you expect to live along traditional lines: woman as homemaker and man as breadwinner?

2. Who will organize the finances?

3. Will household responsibilities be shared equally?

4. Who will assume responsibility for paying bills?

\section{Bibliography}

Amato, P.R., \& Previti, D. 2003, “People's Reasons for Divorcing: Gender, Social Class, the Life Course, and Adjustment", Journal of Family Issues, 24(5), 602626.

Barraket, J., \& Henry-Waring, M.S. 2008, “Getting it on(line): Sociological perspectives on e-dating". Journal of Sociology, 44(2): 14-165.

Bross Bennett LLP (5 January, 2011). “Bross Bennett's Compatibility Quiz: Essential Questions Every Couple Should Ask". Press release. Available at http://www.prnewswire.co.uk/news-releases/bross-bennetts-compatibilityquiz-essential-questions-every-couple-should-ask-156347145.html

Compatibility. 2011. In Oxford Dictionaries Online. Retrieved 29 April 2011. Available at http://oxforddictionaries.com/view/entry/m_en_ gb0978740\#m_en_gb0978740

Crawford, D.W., Houts, R.M., Huston, T.L., \& George, L.J. 2002, “Compatibility, Leisure, and Satisfaction in Marital Relationships", Journal of Marriage and Family, 64(2) 433-449. 
Dearnley, C. 2005, "A reflection on the use of semi-structured interviews", Nurse Researcher, 13(1), 19-28.

Heard, G. 2008, "Partnerships at the 2006 Census: Preliminary Findings". People and Place 16 (1): 31-39.

Hughes, L. 2005, "The adult children of divorce". Journal of Sociology 41(1): 69-86.

Glick, P., DeMorest, J.A., \& Hotze, C.A. 1988, "Self-Monitoring and Beliefs about Partner Compatibility in Romantic Relationships". Personality and Social Psychology Bulletin 14: 485-494.

Gorden, R.L., 1980, Interviewing: Strategy, Techniques and Tactics, Irwin-Dorsey Limited, Illinois, 52-54.

Lindsay, J., \& Dempsey, D. 2009, Families, Relationships and Intimate Life, Oxford University Press, Sydney, 10-266.

Travers, M. 2010, 'Qualitative Interviewing Methods', in M Walter (ed), Social Research Methods, Oxford University Press, Melbourne, VIC, 287-319.

Qu, L. \& Soriano, G. 2004, "Forming Couple Relationships: Adolescents Aspirations and Young Adults' Actualities". Family Matters 68: 43-49. 